\title{
correspondence
}

\section{Prices of scientific journals}

SIR, - The risk of being misquoted from telephonic communications (me to Times Higher Educational Supplement, October 26, 1973) increase when the misquotation is quoted, for $\mathrm{I}$ am the Alec Henderson who figures in Johin Hall's article (Nature, February 15). One original misquotation was that the well known IEEE Transactions becomes the mythical Transactions of the American Association of Electrical and Electronic Engineers: but the desolating fact is that IEEE Trans., having already gone up from $£ 252$ to $£ 321$ this year, has now gone up again to $£ 411-$ a rise of $63 \%$ in a year. On the other hand, it is fair to point out that the quoted increase in price in Current Contents: Life Sciences applied only if one took a new and optional indexing service.

The rate of rise in journal prices is alarming. That of books has hitherto been somewhat less but some alarming trends are evident, particularly in marking up of in-print books in publishers' stocks. Recent correspondence with the American publisher of a work on polymerisation explained that the rise in the United Kingdom price of a book of 416 pages from around $£ 16$ to $£ 24$ was due to floating exchange rates, airfreight charges, warehousing and distribution costs and paper costs - all in the case of a book first published in 1972, not reprinted and listed at the original price in the publisher's catalogue dated 1973-74.

University library budgets in the United Kingdom as a whole were not keeping up with the combined effects of rising prices, diversification within universities and proliferation of literature even before $\mathrm{Mr}$ Barber's cuts in public spending. To these cuts, particularly to that in supplementation for price increases, they are particularly vulnerable because of the large proportion of their expenditure which goes on books and journals and subacademic staff (supplementation of academic salaries being safeguarded): they must therefore receive generous treatment from their universities if they are not to fall further behind in service to their readers. Librarians thus do not need to be urged by Professor Linnett and his co-signatories to "exercise the greatest reticence on subscriptions to new journals"; they already have to do so, against the insistence of their scientists (and others) that exception must be made for the latest expensive journal which is just their thing.

If scientists can reduce the volume and cost of publication, whether by refraining from publishing or by compression, they will themselves reap the benefit of the greater accessibility of what is published since their libraries will be able to afford more of the avail able literature. If $\mathrm{Mr}$ Maxwell's plans for Tetrahedron will reduce by $80 \%$ its price (which I do not suggest is excessive) as well as its bulk, Bubb, Humphreys, Anderson and their fellow librarians will be glad to join with Finniston, Hartnett, Kurti, Thompson and their fellow scientists in praising his "imaginative leadership".

Alex. Anderson

Heriot-Watt University Library,

40 High Street,

Edinburgh EHI ITQ

SIR,-The best way through the scientific prices jungle (Nature, 247, $417 ; 1974)$ is for scientists to give wholehearted support to librarians in their efforts to establish objective criteria of usefulness. It is possible to tell how frequently a title is cited in published papers (especially since the "Journal ranking package" has become available from the Institute for Scientific Information); it is possible to tell how often the title is photocopied, how often the title is borrowed on inter-library loan and how often it is being consulted in the library, if each volume and part has a consultation slip. These may not be very good measures of usefulness but they are much better than no measures at all. All that is lacking is a firm decision on the part of the scientific community that:

(a) No journal should be bought until the cost of borrowing it from the British Lending Library exceeds the cost of buying and storing it on site.

(b) No journal held on site should be maintained unless objective evidence can be produced that it is being used.

I have little doubt that this policy, if strongly backed, would be a major factor both in improving the quality of science journals and in controlling the prices jungle, to the benefit of library users and librarians alike.

\section{P. G. PeAcock}

\section{Library,}

University of Stirling,

Stirling FK9 $4 L A, U K$

\section{Government scientists' pay}

SIR,-It is now widely known that government scientists have been in dispute with the Civil Service Department for over three years because the department has been unwilling to agree on any reasonable criteria for determining the level of scientists' pay. As a result of this long and bitter dispute, government scientists have seen their pay fall, relative io colleagues with whom previously they enjoyed parity, by $20 \%$ and in some cases by even more. Since the government is the major employer of scientists in the United Kingdom, this decline in the pay of government scientists has led to the whole of the science area becoming a depressed industry.

What does not seem to be so widely appreciated is the likely long term effect. The status and success of the United Kingdom in the world have been founded to a large degree on the inventiveness of its people and their achievements in the field of science and technology. What is true of our history seems to us even more true today. Yet, at this critical time, we find that 6,000 places for scientists in the universities are vacant, that fewer young people are studying science at school and that scientists are leaving their chosen careers at an alarming rate to take up other occupations.

Since a decision to adopt a scientific career is often taken at the age of 15 , in effect it takes six years to train a graduaite and nine to train a PhD. Thus the ultimate effect will be to damage the growth of all science-based industries for a decade or more. We believe this is too high a price to pay for an unnecessary dispute.

As responsible members of the scientific community, we look forward to a speedy resolution of the present dispute and to a time when it will again be possible to urge young people to take up science as a socially desirable and reasonably rewarded profession.

\section{J. A. Gibson P. HAWTIN}

The Institution of Professional Civil Servants,

Atomic Energy Branch,

Harwell Section,

AERE, Harwell,

Didcot, Berkshire, UK 